\title{
Preliminary Studies on Solid Lipid Microparticles of Loratadine for the Treatment of Allergic Reactions via the Nasal Route
}

\author{
Melike Üner* and Ecem F Karaman \\ Istanbul University, Faculty of Pharmacy, Department of Pharmaceutical Technology, 34116 Beyazit, Istanbul, Turkey \\ *For correspondence: Email: melikeuner@yahoo.com; Tel: +90 212 4400000; Fax: +90 2124400252
}

Received: 19 April 2013

Revised accepted: 17 May 2013

\begin{abstract}
Purpose: To formulate solid lipid microparticles (SLM) of loratadine (LRT) for the treatment of allergic reactions via the nasal route.

Methods: Microparticles were prepared by emulsion congealing technique. The drug content of microparticles was analysed. Drug/excipient compatibility and crystallinity characteristics of microparticles were investigated by Fourier Transform Infrared Spectroscopy (FT-IR) and differential scanning calorimetry (DSC). Particle size distribution was determined by laser diffraction (LD). Drug release from microparticles was compared to that from conventional vehicles (O/W emulsion, gel and oleageneous cream) using Franz-type diffusion cells.

Results: Drug content of microparticles was $>87.96 \%$. FT-IR and DSC analysis indicated that the drug and excipients were compatible for at least 6 months at room temperature after production. Microparticle size was between $86 \pm 5.63 \mu \mathrm{m}$ and $184 \pm 13.21 \mu \mathrm{m}$ while mean droplet size of $\mathrm{O} / \mathrm{W}$ emulsion was $76 \pm 3.45 \mu \mathrm{m}$. Release profiles of $L R T$ from microparticles were significantly different from those of $\mathrm{O} / \mathrm{W}$ emulsion, gel and oleageneous cream $(p<0.05)$. In the case of conventional vehicles, increase in the hydrophilicity of the vehicles led to increase in drug release rate. Drug release fitted generally to zero order kinetics as well as Korsmeyer-Peppas model for one of the SLM formulations, indicating non-Fickian drug release (super case II transport).

Conclusion: SLM provided LRT release for a longer period than the conventional vehicles. However, in vivo studies are required to ascertain the effectiveness of the formulations.
\end{abstract}

Keywords: Loratadine, Solid lipid microparticles, Allergy, Controlled drug delivery, Transnasal delivery

Tropical Journal of Pharmaceutical Research is indexed by Science Citation Index (SciSearch), Scopus, International Pharmaceutical Abstract, Chemical Abstracts, Embase, Index Copernicus, EBSCO, African Index Medicus, JournalSeek, Journal Citation Reports/Science Edition, Directory of Open Access Journals (DOAJ), African Journal Online, Bioline International, Open-J-Gate and Pharmacy Abstracts

\section{INTRODUCTION}

Loratadine (LRT) is a selective peripheral histamine $\mathrm{H} 1$-receptor antagonist. It is commonly used for the treatment of chronic idiopathic urticaria, allergic rhinitis and asthma by the oral route. Its pharmacological activity is based on inhibition of histamine release from the basophilic granulocytes and the mastocytes where histamine is stored in tissues [1,2]. At the same time, histamine release continues for days as soon as allergic reactions start. This situation significantly affects actual life of patients particularly in case of respiratory and skin reactions like asthma, rhinitis and urticaria. Topical application of LRT could be an alternative to oral administration. Thus, topical applications of LRT including nasal [3], ophthalmic [1] and skin [4] have been reported for the treatment of allergic rhinitis, asthma and various allergic illnesses in the last few years. 
Incorporation of LRT into microparticles is one of the approaches used to provide sustained drug delivery. Nasal application of microparticles containing LRT will introduce both rapid management of allergic reactions and subsequent prolonged drug delivery. Thus, excessive histamine release from granulocytes and mastocytes during can be brought under control and/or prevented. Furthermore, systemic side effects of drugs reported via oral administration can be minimized/eliminated with controlled drug delivery by nasal administration of microparticles [5]. Microparticular carrier systems of LRT may also be used for efficient controlled release inhalation therapy in allergic respiratory reactions $[6,7]$.

The objective of this preliminary study was to formulate SLM of LRT and compare its physicochemical properties, including drug release, with those of conventional vehicles (O/W emulsion, gel and oleageneous cream), for possible nasal administration.

\section{EXPERIMENTAL}

\section{Chemicals}

Loratadine (LRT) was kindly provided by Teva Pharmaceutical Works Private Ltd (Hungary). Glyceryl tristearate, Pluronic ${ }^{\circledR}$ F68, oleic acid, Tween ${ }^{\circledR} 80$ and propylene glycol were purchased from Sigma-Aldrich Inc (Turkey). Precirol ${ }^{\circledR}$ ATO 5 (Gattefossé, France) was generously supplied by B'IOTA Laboratories (Turkey). Carbopol ${ }^{\circledR} 934$ was kindly provided by Lubrizol Corp. (USA). All the other chemicals were of analytical grade.

\section{Preparation of formulations}

SLM was produced by emulsion congealing technique at a temperature at least $15{ }^{\circ} \mathrm{C}$ higher than the melting point of the solid lipid (Table 1) [8]. Lipophilic phase was melted and the drug was added to the lipid melt. A hot aqueous surfactant solution was added. The mixture was homogenized using an Ultra-Turrax T25 homogenizer (Jahnke und Kunkel $\mathrm{GmbH}$, Germany) at $20000 \mathrm{rpm}$ for $20 \mathrm{~min}$. The hot emulsion obtained was kept under the water flowing from a tap for crystallization of the lipid. SLM was obtained by filtration of the dispersion through $S \& S^{5893}$ blue ribbon paper $(2 \mu \mathrm{m}$ pore size, Schleicher \& Schuell, Germany), dried in open air overnight and then transferred to a desiccator containing calcium chloride as the desiccant to keep for 2 days. DSC, FT-IR, LD and study on determination of drug content in microparticles were performed on one part of SLM which was preserved in a tightly closed glass bottle. The other part of SLM was incorporated into a carbomer gel by stirring with a WiseStir HS-100D propeller mixer (Daihan Scientific Co Ltd, Korea) at $50 \mathrm{rpm}$ pending its use for in vitro drug release studies.

An O/W emulsion, gel and an oleageneous cream were also prepared for comparison (Table 1). To prepare the o/w emulsion, drug was added to the liquid oil and the mixture heated to $85{ }^{\circ} \mathrm{C}$. Hot surfactant solution at the same temperature was added to the mixture using the Ultra-Turrax T25 homogenizer. Oleageneous cream was prepared by incorporation of LRT into the lipid/propylene glycol mixture at $85{ }^{\circ} \mathrm{C}$. Gel formulation was obtained by addition of LRT to the proper amount of carbomer hydrogel using a propeller mixer at $100 \mathrm{rpm}$ and room temperature.

\section{Solubility of drug in the release medium}

Phosphate buffer (PBS, pH 7.4) and propylene glycol mixture (60:40) was used as the receptor phase for in vitro release studies. A linear curve was obtained between 2 and $12 \mu \mathrm{g} / \mathrm{ml}$ PBS/propylene glycol mixture (60:40) spectrophotometrically (Shimadzu UV-1601, Japan) at $249 \mathrm{~nm}$ in six replicates $(r=0.9994)$.

Table 1: Composition (\%) of the formulations

\begin{tabular}{|c|c|c|c|c|c|c|c|}
\hline Formulation & SLM1 & SLM2 & SLM3 & SLM4 & O/W emulsion & Gel & Oleageneous cream \\
\hline LRT & 2 & 2 & 2 & 2 & 2 & 2 & 2 \\
\hline Glyceryl tristearate & 18 & 12 & 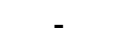 & - & - & - & - \\
\hline Precirol $^{\circledR}$ ATO5 & - & & 18 & 12 & - & - & - \\
\hline Oleic acid & - & 6 & - & 6 & 18 & - & - \\
\hline Pluronic ${ }^{\circledR}$ F68 & - & - & 2 & 2 & 2 & - & - \\
\hline Tween $^{\circledR} 80$ & 2 & 2 & - & - & - & - & - \\
\hline Vaseline & - & - & - & - & - & - & 83 \\
\hline Carbomer & 3 & 3 & 3 & 3 & 3 & 3 & - \\
\hline Propylene glycol & 15 & 15 & 15 & 15 & 15 & 15 & 15 \\
\hline Water & 60 & 60 & 60 & 60 & 60 & 80 & - \\
\hline
\end{tabular}


The solubility of LRT in the receptor phase was studied by the method reported in USP XIX. PBS/propylene glycol (15 ml, 60:40) mixture was placed in four 25-ml flasks. Excess amount of LRT was placed in each flask and the flasks were closed tightly. All the flasks were placed in a constant temperature water bath at $25 \pm 1{ }^{\circ} \mathrm{C}$. The apparatus was maintained under $200 \mathrm{rpm}$ continuous agitation for $24 \mathrm{~h}$ and the dispersion was then filtered through blue ribbon filter paper $\left(S \& S^{5893}\right)$. A measured portion of the clear supernatant was removed using a pipet and diluted. The solubility of LRT in the receptor phase was determined at $249 \mathrm{~nm}$.

\section{Drug content of microparticles}

Appropriate amount of SLM in $100 \mathrm{ml}$ PBS/propylene glycol (60:40) was placed in an ultrasonic bath at $85^{\circ} \mathrm{C}$ to liberate LRT from SLM [9]. After cooling to room temperature, it was filtered through $S \& S^{5893}$ blue ribbon filter paper. The supernatant $(1 \mathrm{ml})$ was taken into a $10 \mathrm{ml}$ volumetric flask and the volume made up to mark with PBS/propylene glycol (60:40). The amount of LRT in the solution was analysed spectrophotometrically at $249 \mathrm{~nm}$. Analysis was performed in triplicate.

\section{FT-IR analysis}

Determination of interaction between LRT and the other ingredients of SLM formulations after 6 months of storage at room temperature in the dark was investigated by FT-IR [10]. Samples were separately scanned over a wave number range of 4000 to $650 \mathrm{~cm}^{-1}$ at a resolution of 4 $\mathrm{cm}^{-1}$ in a Perkin Elmer 100 FT-IR instrument (UK) equipped with Perkin Elmer Spectrum Version 6.0.2 Software. The system was adjusted to the transmission mode. The sample was placed on the sample stage and $100 \mathrm{~N}$ force was applied for scanning.

\section{DSC analysis}

DSC analysis was applied to the drug (LRT), pure lipid and SLM in order to investigate the crystalline behaviour of the lipid drug and druglipid blend [11]. Samples (4 - $5 \mathrm{mg}$ ) were sealed in standard aluminium pans of the apparatus (DSC 204 F1 Phoenix ${ }^{\circledR}$, Netzsch, Germany) and heated from 20 to $170{ }^{\circ} \mathrm{C}$ at a heating rate of 10 $\mathrm{K} / \mathrm{min}$ under a nitrogen flow rate of $20 \mathrm{ml} / \mathrm{min}$. Melting peaks and enthalpies were calculated using the DSC 204 F1 software. The crystalline state of the drug and the lipid in the formulations was determined as the crystallinity index $(\% \mathrm{Cl})$ using Eq 1 [11]

$\mathrm{Cl}(\%)=\left\{\mathrm{me}_{\text {sample }} /\left(\mathrm{me}_{\text {bulk }} \times \mathrm{C}_{\text {bulk }}\right)\right\} 100$

where $\mathrm{me}_{\text {sample }}=$ melting enthalpy of sample $(\mathrm{J} / \mathrm{g}), \mathrm{me}_{\text {bulk }}=$ melting enthalpy of pure drug or bulk solid lipid $(\mathrm{J} / \mathrm{g})$, and $\mathrm{C}_{\text {bulk }}=$ concentration of the drug or solid lipid (\%)

\section{Particle size measurement}

Particle and droplet size distributions of SLM formulations and $\mathrm{O} / \mathrm{W}$ emulsion were determined using a LD instrument equipped with Hydro 2000MU wet sample dispersion unit (Malvern Mastersizer Instrument, UK) [12]. Samples were dispersed in a certain amount of water using the propeller mixer at $50 \mathrm{rpm}$ before the measurements. Measurements were performed in triplicate. Measurement medium was water with a refractive index of 1.33. Particle and droplet size of the formulations were analysed as volumetric distribution (D10, D50 and D90).

\section{In vitro drug release studies}

Plain gel as well as gels containing SLM and $\mathrm{O} / \mathrm{W}$ emulsion were used for this study. The samples $(1 \mathrm{~g})$ were placed in the donor phase over nitrocellulose membrane $(0.45 \mu \mathrm{m}$ pore size, Millipore, Turkey) placed between the two halves of Franz-types diffusion cell with $3.15 \mathrm{~cm}^{2}$ surface area and $33.2 \mathrm{ml}$ receptor volume (Çalışkan Cam Teknik, Turkey) [10]. The receptor phase was PBS/ propylene glycol $(\mathrm{pH}$ $7.4,60: 40)$ at $37 \pm 0.5{ }^{\circ} \mathrm{C}$, and $50 \mathrm{rpm}$ rotation was applied to the receptor phase using magnetic stirrer. The test was carried out under sink conditions for $8 \mathrm{~h}$. Samples $(1 \mathrm{ml})$ were collected at predetermined time intervals and cumulative amount of drug released was determined spectrophotometrically (Shimadzu UV-1601, Japan) at $249 \mathrm{~nm}$ after proper dilution. The cumulative amount of LRT in the release medium was plotted as a function of time. Release profiles were kinetically evaluated by using different models (zero order, first order, and Higuchi square-root, Hixson-Crowell models and Korsmeyer-Peppas model), shown in Table $2[13,14]$.

\section{Statistical analysis}

In vitro drug release data were evaluated using GraphPad Prism software and one-way ANOVA to determine differences between release profiles at 0.05 as the level of significance. 
Table 2: Kinetic models used for the evaluation of drug release from formulations

\begin{tabular}{|c|c|}
\hline \multicolumn{2}{|l|}{ Kinetic models } \\
\hline Zero order & $Q_{\mathrm{t}}=Q_{0}+k_{0 \mathrm{t}}$ \\
\hline First order & $Q_{\mathrm{t}}=Q_{\infty}\left(1-\mathrm{e}^{-k_{1} \mathrm{t}}\right)$ \\
\hline Higuchi & $Q_{\mathrm{t}}=Q_{0}+k_{\mathrm{H}} \mathrm{t}^{1 / 2}$ \\
\hline Hixson-Crowell & $W_{0}^{1 / 3}-W_{t}^{1 / 3}=\mathrm{k} t$ \\
\hline $\begin{array}{l}\text { Korsmeyer- } \\
\text { Peppas }\end{array}$ & $\begin{array}{l}\log \left[Q_{t} / Q_{\infty}\right]=\log k \\
+n \log t\end{array}$ \\
\hline \multicolumn{2}{|c|}{$\begin{array}{l}Q_{t} \text { and } Q_{0} \text {, amounts of drug released at time, } t \text {, and in the } \\
\text { release medium at } t=0 \text {, respectively; } k_{0}, k_{1} \text { and } k_{H} \text { release } \\
\text { constants of the zero order, the first order and Higuchi } \\
\text { square-root models, respectively; } W_{0} \text { and } W_{t} \text {, initial and } \\
\text { remaining amounts (at time } t) \text { of drug in the formulation, } \\
\text { respectively; } \kappa \text {, constant incorporating the surface-volume } \\
\text { relation; } Q_{t} / Q_{\infty}, \text { fractional release of drug; } k \text { and n, kinetic } \\
\text { constant and diffusional release exponent indicative of the } \\
\text { release mechanism. }\end{array}$} \\
\hline
\end{tabular}

\section{RESULTS}

\section{Solubility of drug in the release medium}

The solubility of LRT was $1.152 \pm 0.112 \mathrm{mg} / \mathrm{mL}$ in PBS/propylene glycol (60:40) mixture which was the receptor medium in the in vitro release studies.

\section{Drug content of microparticles}

LRT entrapped by SLM1, SLM2, SLM3 and SLM4 was $87.96 \pm 0.019,95.74 \pm 0.008,88.4289$ 0.011 and $95.51 \pm 0.005 \%$, respectively.

\section{Physicochemical properties of microparticles}

FT-IR profiles were obtained for pure LRT as well as samples of SLM2 and SLM4 containing solid and liquid lipid mixture (Fig 1). The pure drug spectrum showed the characteristic $\mathrm{C}=\mathrm{O}$ stretching band at $1700 \mathrm{~cm}^{-1}, \mathrm{C}=\mathrm{N}$ stretching band at $1643 \mathrm{~cm}^{-1}, \mathrm{C}=\mathrm{C}$ stretching vibrations of benzene ring at $1560 \mathrm{~cm}^{-1}-1434 \mathrm{~cm}^{-1}, \mathrm{~N}-\mathrm{C}$ stretching band at $1385 \mathrm{~cm}^{-1}, \mathrm{C}-\mathrm{O}$ stretching bands at $1222 \mathrm{~cm}^{-1}$ and $997 \mathrm{~cm}^{-1},=\mathrm{C}-\mathrm{H}$ stretching band at $863 \mathrm{~cm}^{-1}$ and $\mathrm{C}-\mathrm{Cl}$ stretching band at $763 \mathrm{~cm}^{-1}$. In the spectra of SLM2 and SLM4, the main characteristic bands of LRT occurred as broader peaks of lower intensity caused by the other ingredients. $\mathrm{C}-\mathrm{H}, \mathrm{N}-\mathrm{H}$ and $\mathrm{O}-\mathrm{H}$ stretching bands for lipids occured at 2956 $2849 \mathrm{~cm}^{-1}$. C $=0$ carbonyl stretching band for lipids was detected at $1741 \mathrm{~cm}^{-1}$ and $1730 \mathrm{~cm}^{-1}$ for SLM2 and SLM4, respectively.

In DSC analysis, LRT gave a melting peak at $137.54^{\circ} \mathrm{C}$ with $74.52 \mathrm{~J} / \mathrm{g}$ melting enthalpy (Fig 2). These values were decreased by incorporation of drug into microparticles (Table 3). Fig 2 and Table 3 also introduce DSC profiles and thermal data of microparticles after 6 months of storage at room temperature.

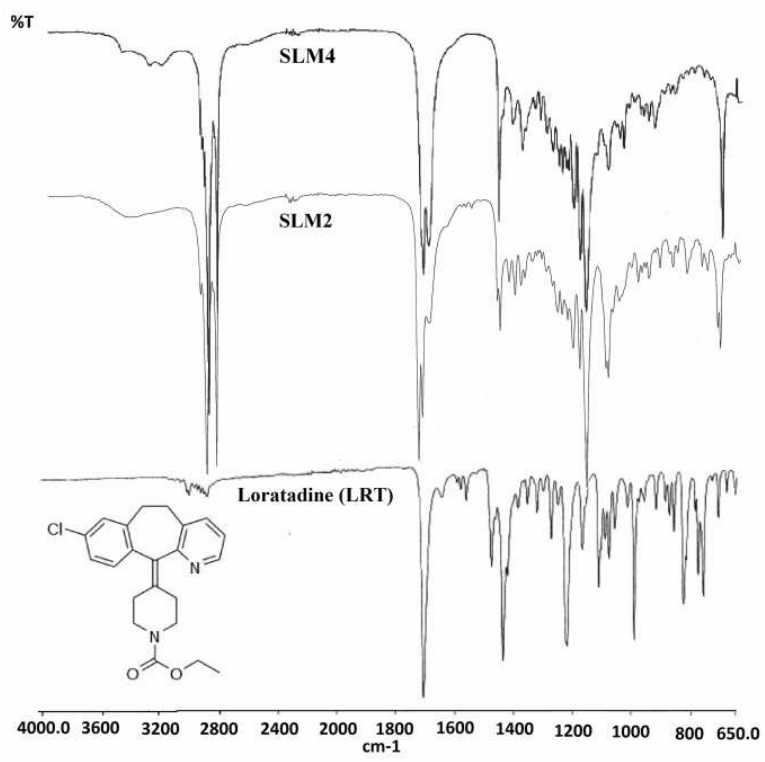

Figure 1: FTIR profiles of SLM2 and SLM4 after 6 months of storage at room temperature

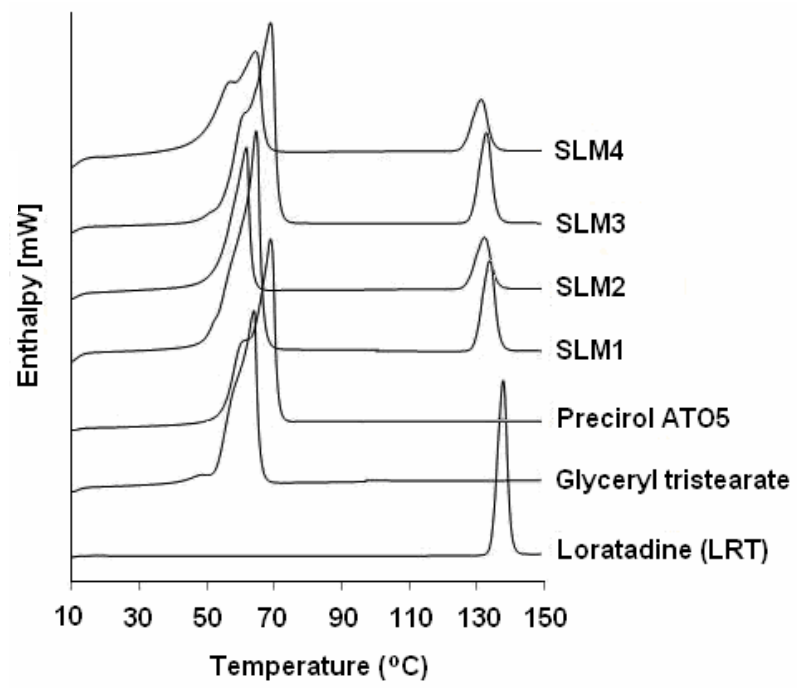

Figure 2: DSC profiles of pure drug (LRT), pure solid lipids and microparticles (SLM1-SLM4) after 6 months of storage at room temperature

Particle and droplet size distribution of SLM and $\mathrm{O} / \mathrm{W}$ emulsion was displayed in Fig 3. SLM containing liquid lipid displayed lower particle size than the formulations that did not contain liquid oil. The mean particle size of SLM4 (formulated with Precirol ${ }^{\circledR}$ ATO5) was $86 \pm 5.57$ $\mu \mathrm{m}$ while the particle size of SLM2 (prepared with glyceryl tristearate) was $110 \pm 10.52 \mu \mathrm{m}$. 
Table 3: DSC parameters of pure drug (LRT), bulk solid lipids and microparticles (SLM1 - SLM4)

\begin{tabular}{|c|c|c|c|c|c|c|}
\hline \multirow[t]{2}{*}{ Formulation } & \multicolumn{2}{|c|}{ Enthalpy $(\Delta \mathrm{H}, \mathbf{J} / \mathbf{g})$} & \multicolumn{2}{|c|}{ Melting point $\left({ }^{\circ} \mathrm{C}\right)$} & \multicolumn{2}{|c|}{$\mathrm{Cl}(\%)$} \\
\hline & Drug & Lipid & Drug & Lipid & Drug & Lipid \\
\hline Pure LRT & 74.52 & - & 137.54 & - & 100 & - \\
\hline Bulk glyceryl tristerate & - & 160.49 & - & 63.29 & - & 100 \\
\hline Bulk Precirol $^{\circledR}$ ATO5 & - & 206.04 & - & 68.17 & - & 100 \\
\hline SLM1 & 37.31 & 137.17 & 133.12 & 63.80 & 37.31 & 94.97 \\
\hline SLM2 & 25.55 & 86.71 & 131.99 & 61.11 & 25.55 & 90.05 \\
\hline SLM3 & 42.58 & 137.55 & 134.58 & 68.11 & 42.58 & 95.23 \\
\hline SLM4 & 27.70 & 110.54 & 132.24 & 63.80 & 27.70 & 89.42 \\
\hline
\end{tabular}

Cl: crystallinity indice

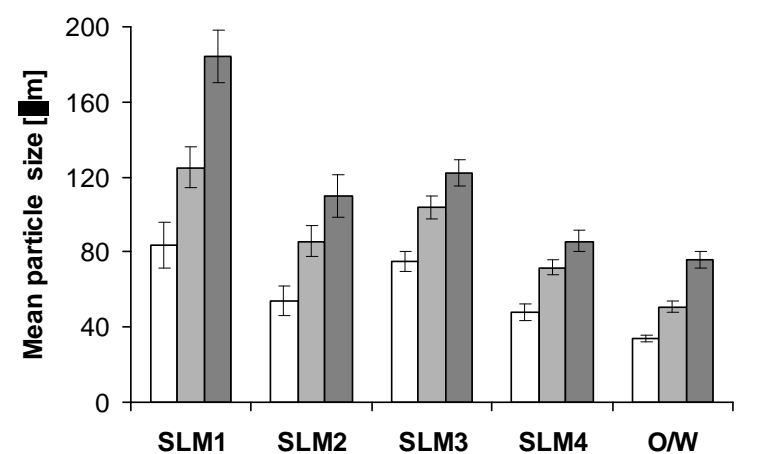

Figure 3: Particle and droplet size distribution of SLM and o/w emulsion. Bars represent D10 (), D50 (匹) and D90 (匹) values of formulations. Note: Laser diffraction (LD) data = volume distribution

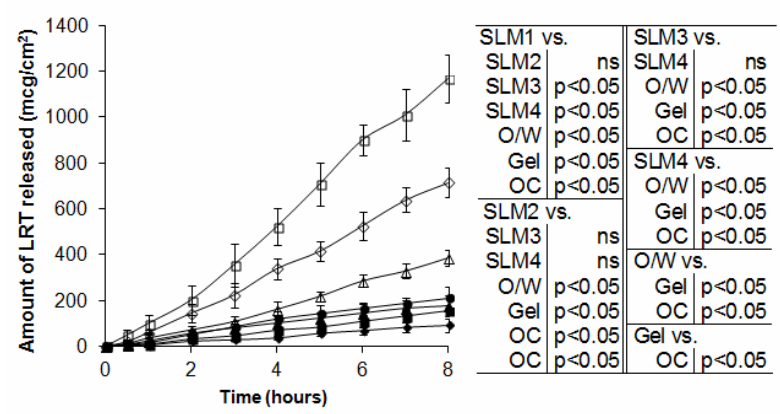

Figure 4: Drug release from formulations; $\downarrow$ SLM1, $=\mathrm{SLM} 2, \boldsymbol{\Delta}=\mathrm{SLM} 3, \bullet=\mathrm{SLM} 4, \diamond=\mathrm{O} / \mathrm{W}, \square=\mathrm{Gel}, \Delta=$ $\mathrm{OC}$; ' $\mathrm{ns}$ ' and $p<0.05$ indicate non-significant and significant differences, respectively.

\section{In vitro drug release}

The solubility of LRT in the release medium $(1.152 \pm 0.112 \mathrm{mg} / \mathrm{ml})$ indicate that drug release occurred under the sink conditions. The highest release was occurred from gel followed by $\mathrm{O} / \mathrm{W}$ emulsion, oleageneous cream and SLM formulations $(p<0.05)$, as shown in Fig 4 . However, insignificant difference was determined for drug release from formulations SLM2, SLM3 and SLM4 $(p>0.05)$ while SLM1 was only statistically similar with SLM2 ( $p>0.05)$.

Analysis of regression on cumulative percentage of drug release versus time curves shows high linearity for zero order kinetic model for the formulations except SLM3 which displayed Higuchi order drug release (Table 4).

\section{DISCUSSION}

Drug entrapment efficiency of microparticles was high because lipophilic materials usually introduce suitable matrix structures to entrap lipophilic drugs. Moreover, addition of liquid lipid into microparticles (SLM2 and SLM4) enhanced percent of drug entrapped since the destruction of crystal order and the resulting amorphous regions in the structure of the matrix provided spaces for drug to be accommodated in the microparticles [15].

FT-IR profiles of microparticles indicated that there was a physical interaction between drug and matrix structure of microparticles. Typical peaks of LRT in the fingerprint area were detected as broader peaks in the same waverange. This also indicates suitability of lipophilic matrix structure comprised of glyceryl tristearate, Precirol ${ }^{\circledR}$ ATO5 and oleic acid for LRT.

DSC profiles displayed a prominent recrystallization behavior of solid lipids. Recrystallization of solid lipids progressed up to a high crystal order during 6 months of storage. 
However, oil incorporation resulted in decrease in melting points and enthalpies with broader Table 4: Drug release rate and kinetic drug release data for the formulations

\begin{tabular}{lcccccc}
\hline Form. & $\begin{array}{c}\text { Release rate } \\
\left(\mathbf{m} \mathbf{c g} / \mathbf{c m}^{2} / \mathbf{h}\right)\end{array}$ & $\begin{array}{c}\text { Zero order } \\
\mathbf{r}\end{array}$ & $\begin{array}{c}\text { First order } \\
\mathbf{r}\end{array}$ & $\begin{array}{c}\text { Higuchi } \\
\mathbf{r}\end{array}$ & $\begin{array}{c}\text { Hixson-Crowell } \\
\mathbf{r}\end{array}$ & $\begin{array}{c}\text { Korsmeyer-Peppas } \\
\mathbf{r}(\mathbf{n})\end{array}$ \\
\hline SLM1 & 12.35 & $\underline{\mathbf{0 . 9 9 5 3}}$ & 0.8818 & 0.9775 & 0.9903 & $0.9862(1.506)$ \\
SLM2 & 19.96 & $\underline{\mathbf{0 . 9 9 7 3}}$ & 0.9325 & 0.9747 & 0.9922 & $0.9949(1.256)$ \\
SLM3 & 22.97 & 0.9940 & 0.8893 & $\underline{\mathbf{0 . 9 9 7 3}}$ & 0.9891 & $0.9913(1.078)$ \\
SLM4 & 27.61 & $\underline{\mathbf{0 . 9 9 5 4}}$ & 0.9120 & 0.9933 & 0.9907 & $0.9936(1.174)$ \\
ONW & 94.38 & $\underline{\mathbf{0 . 9 9 8 8}}$ & 0.9231 & 0.9797 & 0.9936 & $0.9986(1.257)$ \\
Gel & 154.65 & $\underline{\mathbf{0 . 9 9 7 3}}$ & 0.9478 & 0.9756 & 0.9919 & $0.9984(1.177)$ \\
OC & 50.40 & $\underline{\mathbf{0 . 9 9 6 5}}$ & 0.9347 & 0.9711 & 0.9912 & $0.9978(1.222)$ \\
\hline
\end{tabular}

$r=$ correlation coefficient; $n=$ diffusion exponent of release profile (slope). Best fits were bolded.

melting peaks indicating delayed crystallization process of solid lipids. Lower re-crystallization rate of drug was caused by homogeneous distribution of drug through microparticles. Liquid lipid addition also resulted in a decrease in drug re-crystallization more.

Particle size distribution of microparticles was homogeneous. Microparticles containing liquid lipid (SLM2 and SLM4) displayed lower particle size than the others (SLM1 and SLM3). This could be attributed to disruption of crystal order by liquid lipid since crystalline lipid matrix produced a larger particle diameter than amorphous matrix [16]. On the other hand, where the lipophilic phase was which was composed of liquid oil (o/w emulsion) the formulation displayed the lowest droplet size, and this was due to high shear stirring.

Difference in recrystalization behaviour and particle size of SLM did not significantly affect drug release rate. The highest release rate of LRT $\left(154.65 \mathrm{mcg} / \mathrm{cm}^{2} / \mathrm{h}\right)$ was obtained from gel since the drug is not soluble in gel. Increase in lipophilicity of the vehicle led to a decrease in drug release rate of the conventional LRT formulations. The " $n$ " values of KorsmeyerPeppas which is used for explaining release mechanisms indicate involvement of non-Fickian drug release, namely, super case II transport, since " $n$ " was > $0.89[17,18]$.

\section{CONCLUSION}

Suitable SLM of LRT which could potentially be used for nasal application have been prepared. They demonstrated high drug entrapment and good particle size range and distribution for topical application as well as controlled release characteristics. However, further studies are required to ascertain their actual effectiveness for nasal delivery of LRT.

\section{CONFLICT OF INTEREST}

The authors declare that they have no conflict of interest to disclose.

\section{ACKNOWLEDGEMENT}

The authors would like to thank Biofarma Pharmaceutical Industry Co. Inc, Istanbul, Turkey for their support.

A part of this study was presented as a poster at the 8th World Meeting on Pharmaceutics, Biopharmaceutics and Pharmaceutical Technology, Istanbul, Turkey, 19-22 March 2012.

\section{REFERENCES}

1. Chang $C-M$, Farnes EQ, Olejnik O, Chang JN. Ophthalmic compositions containing loratadine. 2003; US Patent 6635654.

2. Hossen MA, Fujii Y, Ogawa M, Takubo M, Tsumoro T, Kamei C. Effect of loratadine on mouse models of atopic dermatitis associated pruritus. Int Immunopharmacol 2005; 5(7-8): 1331-1336.

3. Martinac A, Filipović-Grcić J, Perissutti B, Voinovich $D$, Pavelić Z. Spray-dried chitosan/ethylcellulose microspheres for nasal drug delivery: swelling study and evaluation of in vitro drug release properties. J Microencapsul 2005; 22(5): 549-561.

4. Song JH, Shin SC. Development of the loratadine gel for enhanced transdermal delivery. Drug Dev Ind Pharm 2009; 35(8): 897-903.

5. Van Cauwenberge PB. New data on the safety of loratadine. Drug Invest 1992; 4(4): 283-291.

6. Jaspart S, Bertholet P, Piel G, Dogné JM, Delattre L, Evrard B. Solid lipid microparticles as a sustained release system for pulmonary drug delivery. Eur $J$ Pharm Biopharm 2007; 65(1): 47-56.

7. Mezzena M, Scalia S, Young PM, Traini D. Solid lipid budesonide microparticles for controlled release inhalation therapy. AAPS J 2009; 11(4): 771-778.

8. Mestres JP, Duracher L, Baux C, Vian L, Marti-Mestres G. Benzophenone-3 entrapped in solid lipid microspheres: Formulation and in vitro skin evaluation. Int J Pharm 2010; 400(1-2): 1-7.

9. Üner $M$, Gönüllü Ü, Yener $G$, Altınkurt T. A new approach for preparing a controlled release ketoprofen tablets by using beeswax. Farmaco 2005; 60(1): 27-31. 
10. Yener G, Üner M, Gönüllü Ü, Yıılırım S,Kılıç $P$, Sağlık Aslan S, Barla A. Design of meloxicam and lornoxicam transdermal patches: Preparation, physical characterization, ex vivo and in vivo studies. Chem Pharm Bull 2010; 58(11): 14661473.

11. Siekmann B, Westesen K. Thermoanalysis of the recrystallization process of melt-homogenized glyceride nanoparticles. Colloid Surface B 1994; 3(3): 159-175.

12. Martínez Gómez JM, Csaba N, Fischer S, Sichelstiє292 Kündig TM, Gander B, Johansen P. Sur coating of PLGA microparticles with protamine enhances their immunological performance through facilitated phagocytosis. J Control Release 2008; 130(2): 161-167.

13. Dash S, Murthy PN, Nath L, Chowdhury P. Kinetic modeling on drug release from controlled drug delivery systems. Acta Poloniae Pharm 2010; 67(3): 217-223.
14. Korsmeyer RW, Gurny R, Doelker E, Buri P, Peppas NA. Mechanisms of solute release from porous hydrophilic polymers. Int J Pharm 1983; 15: 25-35.

15. Thatipamula RP, Palem C, Gannu R, Mudragada S, Yamsani $M$. Formulation and in vitro characterization of domperidone loaded solid lipid nanoparticles and nanostructured lipid carriers. DARU J Pharm Sci 2011; 19(1): 23-32.

16. Kovacevic A, Savic S, Vuleta G, Müller RH, Keck CM. Polyhydroxy surfactants for the formulation of lipid nanoparticles (SLN and NLC): Effects on size, physical stability and particle matrix structure. Int $J$ Pharm 2011; 406(1-2): 163-172.

17. Senthil A, Sivakumar $T$, Narayanaswamy VB. Mucoadhesive microspheres of oral anti diabetic drug-Glipizide using different polymers. Pharm Lett 2011; 3(2): 496-506.

18. Jose $S$, Dhanya $K$, Cinu TA, Aleykutty NA. Multiparticulate system for colon targeted delivery of ondansetron. Indian J Pharm Sci 2010; 72(1): 58-64. 